\title{
Development, Validity and Reliability of Dysphagia Assessment Test in Iranian Adults after Stroke
}

\author{
Shiva Ebrahimian Dehaghani ${ }^{1}$, Zahra Khosropoor ${ }^{1}$, Hatef Yousefzadeh ${ }^{1}$, Arya Hamedanchi ${ }^{2}$, \\ ${ }^{1}$ Speech and Language Pathology Department, Shiraz University of Medical Sciences, Shiraz, IR Iran \\ ${ }^{2}$ Iranian Research Center on Aging, University of Social Welfare and Rehabilitation Sciences, Tehran, IR Iran
}

*Corresponding Author: Arya Hamedanchi, MD, MPH, Iranian Research Center on Aging, University of Social Welfare and Rehabilitation Sciences, Kodakyar Ave., Daneshjo Blvd, Evin, Tehran, Iran. Tel: +98-21-22180154, Fax: +98-21-22180154, Email: doctorarya@yahoo.com

\begin{abstract}
Introduction: Many patients who have had strokes suffer from dysphagia which can lead to aspiration pneumonia in $20 \%$ to $25 \%$ of cases. Early assessment of dysphagia has can reduce the risk of death and the cost of medical care. The present study developed a questionnaire to assess dysphagia in adult patients who have suffered strokes and determined the validity and reliability of the content.

Methods: The phases of the study consisted of item generation, analysis of content validity and determination of reliability. To assess the content validity, the primary questionnaire was rated by five experts on swallowing disorders. Items with low scores were removed from the questionnaire. Next, 30 stroke patients were assessed using the final questionnaire and the reliability was assessed by Cronbach's alpha.

Results: The average scores of the items ranged from 0.4 to 1 . Only two items were omitted because of insufficient content validity. The Cronbach's alpha was 0.71 and the standard error of deviation was 4.96, signifying that the reliability was acceptable.

Conclusion: This questionnaire has good content validity and reliability. Although it can be used for clinical assessment of stroke patients who suffer from dysphagia, the concurrent validity should be determined by comparison with to a gold standard such as videofluoroscopy.

Keywords: Dysphagia, Stroke, Assessment, Validity, Reliability, Iran
\end{abstract}

Article History: Received: 27 Dec. 2015; Accepted: 23 Mar. 2016; Online Published: 25 Jun. 2016

Cite this article as: Ebrahimian Dehaghani S, Khosropoor Z, Yousefzadeh H, Hamedanchi A. Dysphagia assessment after stroke development, validity and reliability of dysphagia assessment test in Iranian adults after stroke. Int J Travel Med Glob Health. 2016;4(2):53-6. doi: 10.20286/ijtmgh-04024

\section{Introduction}

Dysphagia is common in patients who have suffered a stroke and can lead to dehydration, malnutrition, aspiration pneumonia, and death. It is important to assess such patients carefully $[1,2]$. Dysphagia can be evaluated through instrumental or clinical assessments. Some clinicians believe that clinical evaluations should only be used for screening and that instrumental assessment must be used to obtain a complete profile of dysphagia patients. Other specialists believe that clinical examination is more accurate and have collected databases for this purpose [3].

Clinical dysphagia assessment tools usually evaluate alertness, oral function, posture, motor speech ability, voice quality, voluntary coughing, eating and water swallowing [4]. Different tools have different objectives. EAT-10 is an appropriate tool for screening patients with dysphagia, but is not specific enough for dysphagia caused by stroke [5] SWAL-QOL is a dysphagia assessment questionnaire with 93 items, making it very time-consuming. Only 14 of the 93 items are dedicated to dysphagia symptoms [6].

The clinical swallowing exam tool from ASHA takes a long time to complete and is not specific to stroke patients [7]. FOIS is very sensitive to changes in functional oral intake and is proper when spontaneous recovery is expected in acute phases of dysphagia [2]. The self-report system inventory is a 19-item tool for assessing the severity of oralpharyngeal dysphagia [8]. MDADI is primarily used to assess quality of life in patients with dysphagia following head and neck cancer [9]. The Italian reflux symptom index is used for primary assessment of dysphagia symptoms in patients with LPR [10].

Clinical screening for dysphagia as developed by Nishiwaki et al. was used to create an inventory for prediction of videofluoroscopic aspiration in patients who have suffered from stroke [4]. Currently, there is no specific tool for dysphagia assessment of stroke patients in Iran. The present study developed a comprehensive inventory for clinical evaluation of dysphagia in patients who have suffered a stroke using items selected from questionnaires developed in previous studies. The psychometric features of the test were then assessed. Logemann believes that administration of water swallowing tests may put patients in danger and that its benefits should be weighed against it probable harm [11]. The present study gathered items to provide a clear understanding of dysphagia symptoms and patients safety during examination.

\section{Methods}

A questionnaire was developed to assess dysphagia in Iranian stroke patients and its content validity and reliability were determined. Participation of the subjects was voluntary and in accordance with ethical principles for medical research involving human subjects. The consent of the subjects was obtained orally and no intervention was involved. In addition, the assessment procedure was completely safe. The method contained the phases of item generation, determination of content validity, and determination of reliability.

\subsection{Item Generation}

Three methods were used to generate items: reference to standard questionnaires, underlying theory, and clinical experience. In the first step, tests for assessment of dysphagia developed before August 2012 were assessed. These tools were found through Google search engine, Science Direct, and PubMed database.

The keywords used are shown in Table 1. Sixteen questionnaires were obtained using these keywords. The International Journal of Travel Medicine and Global Health 2016; 4(2): 53-56 
following inventories were excluded:

- Toronto Bedside Swallowing Screening Test [12]

- Burk dysphagia screening test [13]

- DYMUS [14]

- CMDQ [15]

- MASA [16]

- Dysphagia screening tool in acute stroke patients [17]

- Assessment of swallowing and referral to speech and language in acute stroke [18]

The following questionnaires were selected:

- Clinical swallowing exam [7]

- Clinical screening for dysphagia [4]

- Italian reflux symptom index [10]

- Self-report symptom inventory [8]

- EAT-10 questionnaire [5]

- SWAL-QOL questionnaire [6]

- Anderson dysphagia inventory [9]

- Functional oral intake scale [2]

All items in these questionnaires were collected in one inventory and one item from among those measuring the same function was selected in the item reduction phase. This procedure decreased the number of items to 85.Two more items were added after clinical testing by a dysphagia expert. The researchers then contacted the developers of the original questions and obtained permission to use their items.

The items were then classified according to the underlying theory during development of the six-stage questionnaire. This underlying theory was the four-stage model for swallowing suggested by Magendi and completed by Logemann [11]. The divisions of the inventory were personal information, oral preparatory stage, oral stage, oro- pharyngeal stage, general symptoms of dysphagia and speech, and assessment of respiration and vocalization (Table 2).

\subsection{Content Validity}

Content validity shows the extent to which a test measures what it intends to measure [19]. Five experts in dysphagia studied and rated the items of the questionnaire. The average of the ratings were calculated to determine the content validity as:

\begin{tabular}{|c|c|c|}
\hline & Number of Appropriate & Number of Inappropriate \\
\hline Average & Comments & Comments \\
\hline Judgme & & 2 \\
\hline
\end{tabular}

Scores of 0.5 to 1 signified that an item was fit to remain in the questionnaire. In addition, CVR was calculated as [ne - (N/2)]/(N/2) and CVI was calculated as $\sum \mathrm{CVR} /$ retained numbers.

\subsection{Reliability}

The last phase of the study was determining reliability. To achieve this goal, a target group was assessed using the inventory. Thirty stroke patients from the Namazi and Faghihi hospitals in Shiraz, Iran, participated in this aspect of the study. The participants were chosen by convenience sampling. Participants were evaluated in the acute phase of their stroke after discharge from ICU. Three speech and language pathologists performed the proposed inventory. Each assessment took 30 minutes. Cronbach's alpha, standard deviation and standard error were calculated for the data in SPSS version 20 software.

Table 1. Selected keywords for each database

\begin{tabular}{lc}
\hline Database & Selected Keywords \\
\hline Google & Dysphagia, assessment, tool, validity and reliability \\
PubMed & Dysphagia, assessment, stroke, instrument, questionnaire, validity and reliability \\
Science Direct & Dysphagia, stroke, assessment, screening, test, tool, validity and reliability \\
\hline
\end{tabular}

Table 2. Different stages of Dysphagia assessment test in adults suffering a stroke

\begin{tabular}{|c|c|c|}
\hline Part & Title & 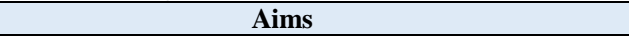 \\
\hline First part & Personal information & $\begin{array}{ll}\text { - } & \text { Personal information } \\
\text { - } & \text { Disease history } \\
\text { - } & \text { Health condition } \\
\text { - } & \text { Feeding method } \\
\text { - } & \text { Mental state }\end{array}$ \\
\hline Second part & Oral preparatory stage & 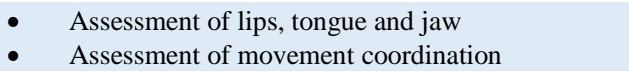 \\
\hline Third part & Oral stage & $\begin{array}{ll}\text { - } & \text { Number of swallowing attempts } \\
\text { - } & \text { The ability to swallow saliva } \\
\text { - } & \text { Drooling } \\
\text { - } & \text { Spitting food and liquids out }\end{array}$ \\
\hline Fourth part & Oro- pharyngeal stage & $\begin{array}{ll}\text { - } & \text { Velum } \\
\text { - } & \text { History of aspiration and pneumonia } \\
\text { - } & \text { Coughing during swallow } \\
\text { - } & \text { Cheeling of food sticking in throat } \\
\text { - } & \text { The ability to swallow different solids and liquids }\end{array}$ \\
\hline Fifth part & General symptoms of Dysphagia & $\begin{array}{ll}\text { - } & \text { Weight loss } \\
\text { - } & \text { Clients independency for eating } \\
\text { - } & \text { Gag reflex } \\
\text { Meal time }\end{array}$ \\
\hline Sixth part & $\begin{array}{c}\text { Assessment of speech, respiration and } \\
\text { vocalization }\end{array}$ & $\begin{array}{ll}\text { - } & \text { Clients Pronunciation } \\
\text { - } & \text { Quality and resonance of voice } \\
\text { - } & \text { Maximum phonation time } \\
\text { - } & \text { Diadochokinetics } \\
\text { - } & \text { Speed and fluency of speech } \\
\text { - } & \text { Loudness } \\
\end{array}$ \\
\hline
\end{tabular}


Ebrahimian Dehaghani S et al. Dysphagia Assessment after Stroke

The questionnaire used for data collection included yes/no questions. Each item was asked by the examiner and the subjects' answers were recorded. A handbook had been developed before testing so that the speech and language pathologist could use the questionnaire without ambiguity. The material in the handbook was compiled from published sources and articles on dysphagia.

The inclusion criteria of the participants were suffering a stroke within one week of the date of examination and possession of sufficient lingual and cognitive skills to be able to understand and follow examiner commands. Exclusion criteria were an anatomical deviation, neurologic disorder, history of head or neck surgery that could affect swallowing or having a tracheotomy.

\section{Results}

The present study designed a questionnaire to assess Iranian stroke patients in three phases.

\subsection{Item Generation}

Items were collected from eight questionnaires and then the number of items was reduced to 85 . Items 21 and 33 were subsequently added based on the clinical experience of a dysphasia expert. The final questionnaire contained 87 questions. In the next step, based on the underlying theory, each question was placed in one of the six groups mentioned in Table 2.

\subsection{Content Validity}

To determine content validity, the average scores of the judgments of experts were calculated. Only two items (41 and 50) were eliminated from the inventory because their scores fell below 0.5.An additional item (liquid test table) was deleted although it had an acceptable score for content validity because it was deemed to be of potential risk to the subjects. The final questionnaire comprised 84 items. Table 3 shows the average ratings. The CVR was determined and then the CVI was calculated to be 0.74, which was considered an acceptable value.

\subsection{Reliability}

The reliability was determined using a target group comprising 19 men and 11 women. The mean age of the participants was 67.4 years. Table 4 shows the descriptive data of the subjects. The Cronbach's alpha was 0.714, the standard deviation was 9.27 and standard error was 4.96 and indicated that the reliability of the questionnaire was acceptable.

Table 3. The amount of average of judgments

\begin{tabular}{lcc}
\hline Items & Percentage & $\begin{array}{c}\text { Average of } \\
\text { Judgments Score }\end{array}$ \\
\hline $\begin{array}{l}1,2,3,5,7,8,9,11,12,21,22, \\
26,27,28,33,36,37,39,40,43,\end{array}$ & \\
44, 45, 47, 48, 52, 53, 55, 58, 63, & $45.97 \%$ & 1 \\
$64,67,75,76,77,80,81,83,85$, & & \\
86 and 87 & & \\
$10,13,14,15,16,19,20,23,24$, & & \\
$25,30,31,32,34,35,38,42,46$, & $39.08 \%$ & \\
$49,51,54,56,57,59,61,62,66$, & & \\
$70,71,72,73,78,82$ and 84 & & 0.6 \\
\hline $17,18,29,51,60,61,63,67,68$, & $12.64 \%$ & 0.4 \\
74 and 79 & $2.29 \%$ & \\
41 and 50 & & \\
\hline
\end{tabular}

Table 4. Subjects' descriptive data

\begin{tabular}{|c|c|c|}
\hline Subject & Age & Sex \\
\hline 1 & 37 & Male \\
\hline 2 & 87 & Male \\
\hline 3 & 71 & Female \\
\hline 4 & 82 & Male \\
\hline 5 & 35 & Female \\
\hline 6 & 76 & Male \\
\hline 7 & 74 & Male \\
\hline 8 & 69 & Male \\
\hline 9 & 67 & Male \\
\hline 10 & 83 & Female \\
\hline 11 & 47 & Female \\
\hline 12 & 64 & Male \\
\hline 13 & 58 & Male \\
\hline 14 & 62 & Female \\
\hline 15 & 47 & Male \\
\hline 16 & 68 & Male \\
\hline 17 & 56 & Male \\
\hline 18 & 71 & Male \\
\hline 19 & 62 & Male \\
\hline 20 & 59 & Female \\
\hline 21 & 63 & Female \\
\hline 22 & 67 & Female \\
\hline 23 & 75 & Male \\
\hline 24 & 84 & Male \\
\hline 25 & 68 & Female \\
\hline 26 & 81 & Female \\
\hline 27 & 73 & Female \\
\hline 28 & 72 & Male \\
\hline 29 & 85 & Male \\
\hline 30 & 79 & Male \\
\hline
\end{tabular}

\section{Discussion}

Iran lacks a reliable and valid tool for assessing dysphagia in stroke patients. Because dysphagia has a close relationship with survival and mortality, it is important to assess these patients comprehensively without putting them in danger. Some tools established for screening of dysphagia specifically address its development after a stroke. Other inventories assess the symptoms or its severity of dysphagia caused by disease.

The proposed inventory is an 84-item inventory used to evaluate dysphagia symptoms. The items requiring a water swallowing exam was eliminated, although it is included in all previous dysphagia evaluation inventories. This the main difference between the proposed inventory and others. The motivation for its omission is the research by Logemann et al. on potential harm to patients from the water swallowing exam. They found that, although many researchers have shown the water swallowing exam to be a good predictor of aspiration in dysphasic patients, the pros and cons require further investigation [11].

Another characteristic of the proposed inventory not seen in previous inventories is that items related to swallowing were separated into groups to provide the opportunity to more easily access the information. Only two psychometric features of the inventory were measured: content validity and internal consistency. The target group was 35 dysphagia patients who had recently suffered a stroke and the results demonstrated that the inventory validity and reliability are acceptable. It can be used for safe clinical evaluation of dysphagia in stroke patients.

An additional consideration was that the examiners were undergraduate students of speech and language pathology and it was suggested that administration of the inventory may not be challenging for them. In fact, both the examiners and the patients were comfortable with it. This demonstrates that the items of inventory were easy to administer and that 
patient safety was protected. It also required a relatively short time to complete.

The limitations of the research were that only two psychometric features of the inventory were measured. In addition, the sample size could have been larger. Future investigation should measure other psychometric features of the inventory. Moreover, researchers should determine the necessity of the water swallowing test to allow its omission from the inventory to avoid possible harm to patients.

\section{Conclusion}

This inventory is a safe, easily administered tool for clinical evaluation of dysphagia patients following stroke. Because there is no inventory for this purpose in Iran, it is a beneficial tool for researchers and clinicians to get a clear picture of dysphagia symptoms.

\section{Acknowledgments}

The authors would like to thank the "Clinical Research Development Unit" of Baqiyatallah Hospital for their kind cooperation.

\section{Author Contributions}

All authors were involved in the study design, data collection, interpretation of results and preparation of the manuscript.

\section{Financial Disclosure}

The authors declare no financial advantages that require disclosure.

\section{Funding/Support}

None received.

\section{Reference}

1. Perry L, Love CP. Screening for dysphagia and aspiration in acute stroke: a systematic review. Dysphagia. 2001;16(1):7-18. doi: 10.1007/PL00021290

2. Crary MA, Mann GDC, Groher ME. Initial psychometric assessment of a functional oral intake scale for dysphagia in stroke patients. Arch Phys Med Rehabil. 2005;86(8):1516-20. doi: 10.1016/j.apmr.2004.11.049

3. González-Fernández M, Sein MT, Palmer JB. Clinical experience using the Mann assessment of swallowing ability for identification of patients at risk for aspiration in a mixed-disease population. Am J Speech Lang Pathol. 2011;20(4):331-6. doi: 10.1044/10580360(2011/10-0082)
4. Nishiwaki K, Tsuji T, Liu M, Hase K, Tanaka N, Fujiwara T. Identification of a simple screening tool for dysphagia in patients with stroke using factor analysis of multiple dysphagia variables. J Rehabil Med. 2005;37(4):247-51. doi: 10.1080/16501970510026999

5. Belafsky PC, Mouadeb DA, Rees CJ, Pryor JC, Postma GN, Allen J, et al. Validity and reliability of the Eating Assessment Tool (EAT10). Ann Otol Rhinol Laryngol. 2008;117(12):919-24. doi: 10.1177/000348940811701210

6. Rinkel RN, Verdonck-de Leeuw IM, Langendijk JA, van Reij EJ, Aaronson NK, Leemans CR. The psychometric and clinical validity of the SWAL-QOL questionnaire in evaluating swallowing problems experienced by patients with oral and oropharyngeal cancer. Oral Oncol. 2009;45(8):e67-71. doi:10.1016/j.oraloncology.2009.03.003

7. Patel R. Assessment of swallowing disorders. SwallowingPhysiology, Disorders, Diagnosis and Therapy: Springer; 2015. p. 49-60. doi: 10.1007/978-81-322-2419-8_4

8. Wallace KL, Middleton S, Cook IJ. Development and validation of a self-report symptom inventory to assess the severity of oralpharyngeal dysphagia. Gastroenterol. 2000;118(4):678-87. doi: 10.1016/S0016-5085(00)70137-5

9. Chen AY, Frankowski R, Bishop-Leone J, Hebert T, Leyk S, Lewin $\mathrm{J}$, et al. The development and validation of a dysphagia-specific quality-of-life questionnaire for patients with head and neck cancer: the MD Anderson dysphagia inventory. Arch Otolaryngol Head Neck Surg. 2001;127(7):870-6.

10. Schindler A, Mozzanica F, Ginocchio D, Peri A, Bottero A, Ottaviani F. Reliability and clinical validity of the Italian Reflux Symptom Index. J Voice. 2010;24(3):354-8. doi: 10.1016/j.jvoice.2008.08.008

11. Logemann JA. The evaluation and treatment of swallowing disorders Curr Opin Otolaryngol Head Neck Surg. 1998;6(6):395-400. doi: 10.1097/00020840-199812000-00008

12. Martino R, Silver F, Teasell R, Bayley M, Nicholson G, Streiner DL et al. The toronto bedside swallowing screening test (TOR-BSST) development and validation of a dysphagia screening tool for patients with stroke. Stroke. 2009;40(2):555-61. doi: 10.1161/STROKEAHA.107.510370

13. DePippo KL, Holas MA, Reding MJ. The Burke dysphagia screening test: validation of its use in patients with stroke. Arch Phys Med Rehabil. 1994;75(12):1284-6.

14. Bergamaschi R, Minguzzi S, Amato MP, Patti F, Bonavita S, Grasso $\mathrm{MG}$, et al. Validation of the DYMUS questionnaire for the assessment of dysphagia in multiple sclerosis. Funct Neurol. 2009;24(3):159.

15. Colodny N. Validation of the caregiver mealtime and dysphagia questionnaire (CMDQ). Dysphagia. 2008;23(1):47-58. doi: 10.1007/s00455-007-9094-3

16. Mann G. MASA, the mann assessment of swallowing ability: Cengage Learning; 2002.

17. Edmiaston J, Connor LT, Loehr L, Nassief A. Validation of a dysphagia screening tool in acute stroke patients. Am J Crit Care. 2010;19(4):357-64. doi: 10.4037/ajcc2009961

18. Hinds N, Wiles C. Assessment of swallowing and referral to speech and language therapists in acute stroke. QJM. 1998;91(12):829-35. doi: 10.1093/qjmed/91.12.829

19. Fraenkel JR, Wallen NE, Hyun HH. How to design and evaluate research in education: McGraw-Hill New York; 1993. 